\title{
Unusual presentation of ocular Toxocara infestation
}

\author{
P. HARDY SMITH AND G. H. GREER \\ The Royal Melbourne Hospital and the Royal Victorian Eye and Ear Hospital, Melbourne, Australia
}

Since Wilder (1950) first demonstrated the presence of nematode larvae (subsequently identified as second-stage larvae of Toxocara canis) in a number of eyes enucleated for suspected retinoblastoma, the possibility that such infestation may be the aetiological factor in certain cases of uveitis and endophthalmitis has been well recognized. Many reports of such infestation proven by identification of the worm in serial sections have now appeared in the literature, but the mode of presentation of the case to be described appears sufficiently unusual to be worth reporting.

\section{Case report}

The mother of the patient, a 3-year-old girl, gave the history that for the previous 10 days the child's right eye had appeared injected and mildly irritable. The onset of the inflammation coincided with an apparent attack of shingles over the area of the left fourth thoracic dermatome, and 24 hours before the ophthalmological consultation the mother had noted a white spot on the lower portion of the right iris and this had gradually increased in size.

The child had been subject to recurrent middle ear infections for the past year, and seemed to suffer from more than the usual number of coughs and colds. In the light of subsequent findings, particular enquiry was made concerning contact with dogs, but the family had never owned a dog and their home environment was such that contact with areas contaminated by dogs appeared unlikely.

\section{Examination}

The eye showed very slight conjunctival injection and a $3 \mathrm{~mm}$. hypopyon was present. There was a one-plus aqueous flare and the anterior chamber showed a number of circulating cells which appeared large and slightly pigmented. A thin fibrinous exudate occluded the pupil, but full pupillary dilation was attained quite easily and binocular indirect ophthalmoscopy revealed no fundus pathology other than a small white punched-out area adjacent to the upper temporal vessels anterior to the equator; this area appeared quite inactive.

\section{Treatment}

Topical prednisolone and atropine was given and 2 days later the hypopyon had completely cleared although there were still some circulating cells. An excellent view of the whole of the periphery of the fundus as far forward as the ora serrata could now be obtained and no other pathology could be seen.

Routine investigations, including physical examination, chest $x$ ray, and full blood examination were normal, with the exception that the blood eosinophil count was 4 per cent.; in the light of subsequent events, this was probably of significance.

\section{Progress}

Over the next few weeks the cells in the anterior chamber cleared and the eye whitened. However, 4 weeks after the initial presentation, fundus examination revealed a yellowish-white mass at the ora 
serrata in the upper temporal quadrant. This mass was approximately four disc diameters in size and appeared raised, with several irregular flocculent strands radiating from it into the vitreous. Examination under anaesthesia confirmed these findings, and also confirmed the presence of the inactive punched-out lesion previously described. The remainder of the examination of the involved eye and of the fellow-eye was normal. $X$ rays of the eye showed no calcification. The child was seen by three other ophthalmologists in consultation; it was considered that, although there was some possibility that the appearances were due to nematode infestation or other pathology, the presence of retinoblastoma could not be excluded. It was also considered that the situation of the mass and the possibility that it might be part of a diffuse infiltrating retinoblastoma were a contraindication to radiotherapy.

The eye was therefore enucleated.

At the time of the examination there was no specific test for Toxocara immediately available in Australia, but Dr. C. Dobson of the Department of Parasitology, University of Queensland, has examined the patient's serum against Toxocara canis and other helminths, using passive reversed Arthus and passive cutaneous anaphylaxis tests in guinea-pigs. He reported the test positive to Toxocara canis only, although the test was much weaker than other positive sera and the control from the dog (the test was performed 5 months after enucleation).

\section{Pathology (Figs I and 2)}

\section{MAGROSCOPIG APPEARANCES}

The cornea is clear. Horizontal opening section above the disc. The retina is in place and the disc and macula are somewhat prominent. There is a greyish-white localized thickening of the retina at the ora serrata on the temporal side astride the horizontal meridian. From this thickening, thin strands like threads of cotton-wool radiate into the vitreous and over the pars plana. The vitreous is otherwise clear and gelatinous except for a few small clumps of cells. The lens is clear. There is some retinal detachment, which transilluminates, inferior to the focus at the ora serrata.

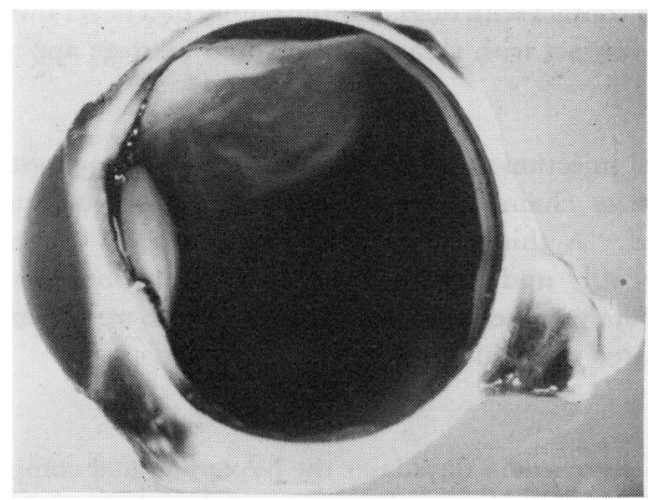

F I G. I Macroscopic appearance on sagittal section, showing anterior fundus lesion

FIG. 2 Microscopic appearance, showing segment of organism. $\times 270$

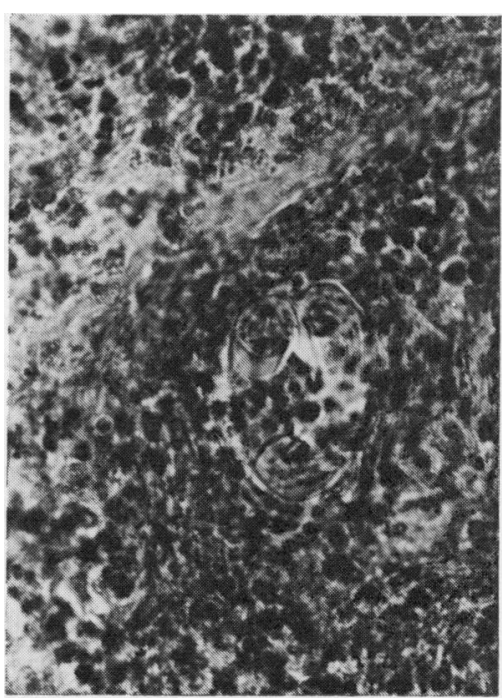

\section{SEGTIONS}

These show a localized granulomatous inflammatory reaction at the ora serrata involving the vitreous, retina, and ciliary epithelium. The reaction has broken through the ciliary 
epithelium into the stromal tissue of the pars plana and anterior choroid. The granuloma consists of fibrin, lymphocytes, epithelioid cells, foreign body giant cells, and innumerable eosinophils.

In two of the 165 serial sections through the granuloma, part of a nematode larva is present lying coiled among the inflammatory cells. The larva is $18 \mu$ in diameter and approximately $250 \mu$ in length. Where it is cut in transverse section, the following features can be recognized - a refractile cuticle with lateral spines or alae and two granular excretory columns. Where the larva is cut longitudinally, small body nuclei can be discerned arranged in rows on either side of a central tube. No mouth parts can be identified.

Mononuclear cells and eosinophils have migrated from the granulomatous focus into the vitreous. There is an inflammatory infiltration of the iris and trabecular meshwork by plasma cells and eosinophils and a few small keratic precipitates. The temporal choroid is focally infiltrated by lymphocytes and eosinophils. The retina is thickened by oedema, especially at the macula, and there is lymphocytic infiltration of the walls of the retinal blood vessels.

\section{DIAGNOSIS}

Nematode endophthalmitis (Toxocara canis larval infestation).

The sections were also examined by Professor J. F. A. Sprent of the University of Queensland who confirmed the diagnosis of Toxocara canis.

\section{Comment}

This case of ocular Toxocara canis infestation was of interest in that the presentation was in the nature of an acute anterior uveitis with hypopyon with subsequent development of a retinal mass. The more usual method of presentation appears to be either as a chronic uveitis or endophthalmitis often with associated retinal detachment or as a solitary retinal granuloma at the posterior pole (Duguid, 196ra, b). In Duguid's series of cases a discrete lesion was not seen in the peripheral fundus other than in cases of chronic endophthalmitis with retinal detachment. Hogan, Kimura, and O'Connor (I965), discussing peripheral retinitis and chronic cyclitis in children, felt that some of their cases might have been due to nematode infestation but they described no specific diagnostic features in these cases.

Perkins (1966) reported a number of cases of peripheral choroiditis in children thought to be possibly due to Toxocara; the diagnosis was based on blood eosinophil count, a positive skin-test to Toxocara antigen, and a history of contact with dogs, but none of these eyes was removed and sectioned. Perkins felt that Toxocara infestation was a probable or possible cause of the uveitis in ro per cent. of his series. He mentioned one case of acute anterior uveitis with a hypopyon and raised blood eosinophil count but gave no further details.

When the child presented no test was immediately available in Australia which might have been helpful in diagnosing Toxocara canis infestation, and because of the hypopyon with large cells in the anterior chamber and the subsequent appearance of a peripheral retinal mass it was considered that the condition might represent a diffuse infiltrating retinoblastoma as described by Schofield (1960). The possibility of retinoblastoma was also enhanced by the report of Howard and Ellsworth (I966) that, in their series of retinoblastomata, 26 per cent. of eyes showed the sole or major growth of tumour in the periphery. In retrospect it is probable that anterior chamber aspiration and examination of the 
aspirate would have helped in the diagnosis. The fact the that hypopyon cleared rapidly with topical steroids is also in keeping with the basically inflammatory nature of the disease. When the mass in the fundus became evident, a subconjunctival injection of depot corticosteroids as described by Nolan (1968) would possibly have been helpful as a diagnostic measure, as a retinoblastoma would not be expected to show any significant change following this treatment.

\section{Summary}

A case of ocular Toxocara canis infestation presenting as an acute uveitis with hypopyon is reported. The eye was enucleated after the development of an anterior retinal mass which was thought to be a retinoblastoma. Serial sections of the mass revealed the presence of a Toxocara canis larva.

\section{References}

Duguid, I. м. (1961a) Brit. F. Ophthal., 45, 705

$$
\text { (196r Ib) Ibid., 45, 789 }
$$

hOGAN, M. J., KIMURA, S. J., and o'ConNor, G. R. (1965) Trans. ophthal. Soc. U.K., 85, 39

hoWARD, G. M., and EllsWORTh, R. M. (1966) Amer. F. Ophthal., 62, 243

NOLAN, J. (1968) Brit. F. Ophthal., 52, 276

PERKINS, E. s. (1966) Ibid., 50, I69

SCHOFIELD, P. B. (I960) Ibid., 44, 35

Wilder, H. C. (1950) Trans. Amer. Acad. Ophthal. Otolaryng., 55, 99 